\title{
O PARQUE AUGUSTA E A MULTIPLICAÇÃO DO POTENCIAL CONSTRUTIVO: A TDC PARA A IMPLANTTAÇÃO DE PARQUES MUNICIPAIS NO PDE-SP DE 2014
}

\author{
Amanda Paulista de Souza* \\ Flávia Taliberti Peretto** \\ He Nem Kim Seo ${ }^{* * *}$ \\ * Universidade Nove de Julho, Programa de Pós-graduação em Cidades Inteligentes e Sustentáveis, São Paulo, \\ SP, Brasil \\ ** Universidade de São Paulo, Programa de Pós-graduação da Faculdade de Arquitetura e Urbanismo, São \\ Paulo, SP, Brasil \\ *** University of Seoul, International School of Urban Science, Master in Urban Administration and Planning, \\ Seul, Coreia do Sul
}

\section{Resumo}

A Transferência do Direito de Construir (TDC) é um instrumento urbanístico que permite a transferência ou a alienação do potencial construtivo de um imóvel munido de interesse público. No município de São Paulo, a modalidade de TDC para a implantação de Parques Municipais tem chamado atenção, especialmente após sua utilização no acordo a respeito do Parque Augusta firmado entre prefeitura, Ministério Público, sociedade civil e as construtoras Cyrela e Setin. O presente artigo tem como objetivo analisar as transferências realizadas como resultado das Declarações de Potencial Construtivo Passivel de Transferência emitidas para os terrenos do Parque Augusta. Para isso, com base nos dados coletados até julho de 2020, o estudo realizou simulações de TDC para os parques da cidade de São Paulo a fim de evidenciar a multiplicação exacerbada de potencial construtivo decorrente da modalidade, bem como para apontar os possíveis efeitos dessa multiplicação e indicar as disposições legais que geraram tal distorção, exclusiva da modalidade de TDC para Parques Municipais.

Palavras-chave

Transferência do Direito de Construir; Parque Augusta; Estatuto da Cidade; Plano Diretor; Política Urbana; Legislação Urbanística. 


\title{
PARQUE AUGUSTA AND THE MULTIPLICATION OF CONSTRUCTION POTENTIAL: THE TRANSFER OF BUILDING RIGHTS FOR THE IMPLEMENTATION OF MUNICIPAL PARKS IN THE 2014 SÃO PAULO MASTER PLAN
}

\author{
Amanda Paulista de Souza* \\ Flávia Taliberti Peretto** \\ He Nem Kim Seo ${ }^{* * *}$ \\ * Universidade Nove de Julho, Programa de Pós-graduação em Cidades Inteligentes e Sustentáveis, São Paulo, \\ SP, Brazil \\ ** Universidade de São Paulo, Programa de Pós-graduação da Faculdade de Arquitetura e Urbanismo, São \\ Paulo, SP, Brazil \\ *** University of Seoul, International School of Urban Science, Master in Urban Administration and Planning, \\ Seul, South Korea
}

\begin{abstract}
The Transfer of Building Rights (TDC) is an urban policy instrument which allows the transfer or alienates the right to build of a property with public interest. In the City of São Paulo, the TDC for Public Parks has strike attention, especially after its use in the agreement regarding Parque Augusta between City Hall, Public Ministry, civil society, and the construction companies Cyrela and Setin. This article aims to analyze the transfers from the Declarations of Transferable Construction Potential issued to the lands of Parque Augusta. For this, based on the data collected up to July 2020, the study carried out TDC simulations for the parks of the city of São Paulo in order to show the exacerbated multiplication of construction potential resulting from this modality. It also points out the possible effects of such multiplication and indicates the legal provisions that led to such distortion, exclusive of the TDC modality for Municipal Parks.
\end{abstract}

Keywords

Transfer of Building Rights; Augusta Park; City Statute; Master Plan; Urban Policy; Urban Legislation. 


\section{O PARQUE AUGUSTA E A MULTIPLICAÇÃO DO POTENCIAL CONSTRUTIVO: A TDC PARA A IMPLANTAÇÃO DE PARQUES MUNICIPAIS NO PDE-SP DE 2014}

Amanda Paulista de Souza

Flávia Taliberti Peretto

He Nem Kim Seo

Introdução

A Transferência do Direito de Construir (TDC) é um instrumento que, em linhas gerais, permite ao proprietário de um imóvel considerado de interesse público transferir ou alienar, para outro imóvel, o potencial construtivo correspondente ao seu direito de construir, nos casos em que este não puder ser exercido total ou parcialmente no terreno de origem. Definido como um instituto jurídico e político pelo Estatuto da Cidade (BRASIL, 2001), ele tem despertado, no município de São Paulo, particular interesse do mercado após sua regulamentação mais recente pelo Plano Diretor Estratégico (PDE), aprovado pela Lei Municipal $n^{\circ}$ 16.050, de 31 de julho de 2014 (SÃO PAULO, 2014).

Atualmente, a TDC viabiliza o cumprimento das seguintes finalidades na cidade de São Paulo: a preservação de imóveis tombados e de significativo valor histórico e cultural; a execução de melhoramentos viários voltados à implantação de corredores de ônibus; a realização de programas de regularização fundiária e provisão de Habitação de Interesse Social (HIS); a implantação de Parques Municipais e a proteção de áreas verdes particulares.

Entretanto, apesar dessas diversas finalidades, a modalidade que envolve a doação de imóvel ao Poder Público andava a passos lentos e ocupava uma posição coadjuvante no universo emergente da TDC, ferramenta majoritariamente utilizada para a preservação de bens tombados. Até então sem despertar muita atenção, a modalidade em foco ganhou destaque ao se apresentar como a solução ao entrave do Parque Augusta, que vinha acontecendo desde antes da revisão do 
PDE-2014. O problema foi resolvido com o acordo firmado entre Ministério Público, proprietárias (Cyrela e Setin), prefeitura e sociedade civil, homologado pela Justiça em setembro de 2018. Mais do que permitir selar o citado acordo, essa modalidade da TDC se revelou, depois do referido caso, uma empreitada valiosa e surpreendentemente rentável para o mercado privado de potencial construtivo.

No presente artigo, serão tecidas considerações acerca da TDC no município de São Paulo, com ênfase na modalidade que envolve a doação de imóvel ao Poder Público para a implantação de Parques Municipais. Com base nos dados da TDC coletados até julho de 2020, o estudo ora apresentado realizou simulações de um conjunto de áreas passíveis de doação ao município para a implantação de parques, em especial o estudo de caso da área do Parque Augusta. Demonstramos, assim, como o mecanismo formulado para a efetivação dessa modalidade promove uma multiplicação do potencial construtivo transferível quando comparado ao potencial construtivo que poderia, de fato, ser exercido no imóvel - multiplicação inexistente nas demais modalidades de TDC.

Para tanto, iniciaremos nossa abordagem do tema com uma breve introdução à disciplina da TDC em São Paulo, dando destaque à regulamentação vigente consubstanciada no PDE-2014. Em seguida, nos debruçaremos particularmente sobre a modalidade da TDC com doação de imóvel para implantação de Parques Municipais, detalhando tanto os dados obtidos por meio das simulações realizadas como aqueles relativos às transferências já efetivadas pelo Parque Augusta, os quais indicam um padrão de multiplicação do potencial construtivo transferível. Por fim, são apresentados conclusões e apontamentos sobre os prováveis impactos da utilização dessa ferramenta na produção da cidade de São Paulo.

\section{A TDC no município de São Paulo}

O Estatuto da Cidade é um marco legislativo para a TDC ao estabelecê-la como um instituto jurídico e político aplicável em todo o território nacional, a ser regulamentada por lei municipal baseada em Plano Diretor correspondente'. Todavia, o Estatuto da Cidade discorre resumidamente sobre o tema, atendo-se a conceituar o instituto como a possibilidade, aos proprietários, de alienar ou exercer o direito de construir correspondente aos imóveis que estejam adequados ao cumprimento das seguintes finalidades: i) implantação de equipamentos urbanos e comunitários; ii) preservação, quando o imóvel for considerado de interesse histórico, ambiental, paisagístico, social ou cultural; iii) implementação de programas de regularização fundiária, urbanização de áreas ocupadas por população de baixa renda e habitação de interesse social.

1. Ver arts. $4^{\circ}$, V, “'o”,' e 35 do Estatuto da Cidade. 
Em outras palavras, caso um proprietário tenha um imóvel tombado e, em virtude das restrições do tombamento, não puder exercer em seu próprio lote o direito de construir que ainda lhe cabe, ele poderá fazê-lo em outro local, de maneira a garantir a adequada preservação do bem e de não ver prejudicado seu direito de construir. Nos termos do Estatuto da Cidade, é possível, ainda, que o proprietário ofereça em doação o imóvel, se isso se mostrar interessante ao cumprimento de uma das finalidades elencadas; seria o caso, por exemplo, do proprietário que doa à municipalidade um imóvel ocupado por famílias de baixa renda que poderá ser objeto de regularização fundiária, em troca do exercício ou da alienação do direito de construir correspondente ao imóvel doado (ROLNIK, 2002).

Especificamente no município de São Paulo, a TDC já estava disciplinada e vinha sendo aplicada antes da aprovação do Estatuto da Cidade. A primeira iniciativa municipal nesse sentido foi concretizada por meio da Lei $n^{\circ} 9.725$, de 1984, que tratava da TDC exclusivamente voltada aos imóveis de interesse histórico e cultural, enquadrados na zona de uso especial Z8-200². A ideia era de que a TDC atuasse como um instrumento de incentivo à preservação e à conservação dos aproximadamente 248 imóveis $^{3}$ demarcados como Z8-200, os quais poderiam utilizar ou alienar seu potencial construtivo correspondente, desde que a transferência ficasse circunscrita aos imóveis inseridos na zona de uso contígua, o que imprimia um caráter mais limitado à efetivação do instrumento.

Ainda que tal iniciativa nem sempre seja avaliada como um sucesso - uma vez que apenas três imóveis se utilizaram da TDC nos termos da lei de 1984, conforme Peretto (2020) -, seu caráter inovador é inegável. É preciso ter em mente que foi no Brasil da década de 1970 que se iniciaram as discussões sobre a TDC e sobre o conceito do "solo criado", os quais pressupõem questões delicadas do ponto de vista jurídico, como a separação entre o direito de propriedade, regulamentado pela legislação civil federal, e o direito de construir sobre o lote adquirido, regulamentado, em geral, pelo plano diretor municipal e leis de uso e ocupação do solo (REZENDE, 2009); ou, ainda, a legitimidade do Estado para limitar o exercício do direito de propriedade individual por meio da fixação de um coeficiente de aproveitamento para cada lote. Tais pressupostos foram debatidos e tratados na

\footnotetext{
2. Em São Paulo, a primeira iniciativa voltada à preservação de imóveis de valor cultural data de 1974, quando a Coordenadoria de Gestão e de Planejamento (Cogep) realizou o inventário de bens dignos de preservação na área central da cidade. Essa listagem foi incorporada à Lei $n^{\circ}$ 8.328/1975, que criou as zonas de uso Z8-200, cujo objetivo era preservar esses imóveis.

3. Número de edificações consideradas de valor histórico e cultural para a cidade de São Paulo, protegidas pelas Leis Municipais $n^{\circ} 8.328 / 75, n^{\circ} 8.759 / 78, n^{\circ} 8.769 / 78, n^{\circ} 8.848 / 78$ e $n^{\circ}$ 9.725/84, que demarcaram esses imóveis nas zonas de uso especial Z8-200.
} 
chamada "Carta de Embu”, de 1976, na qual, contemporaneamente a países como Estados Unidos e Itália, foram consolidadas as bases do conceito de solo criado e de instrumentos dele decorrentes, como a TDC e a Outorga Onerosa do Direito de Construir (OODC).

A Lei $n^{\circ}$ 9.725/84 se apresenta como uma normativa inovadora, pois se propôs disciplinar as primeiras experiências da TDC no Brasil. Vale ressaltar, no entanto, que a legislação mencionada dispunha de uma única finalidade autorizadora para o exercício da TDC, fato que acabou contribuindo para sua caracterização inicial como um instrumento de proteção ao patrimônio histórico, mais tarde reforçada com a aprovação da Lei Municipal no 12.349/1997, que instituiu a Operação Urbana Centro, cuja disciplina vinculava e circunscrevia, novamente, a possibilidade de TDC aos imóveis de valor histórico e cultural (PERETTO, 2018).

Foi somente com a primeira revisão do marco regulatório urbanístico municipal ${ }^{4}$, realizada no início da década de 2000, que a vinculação exclusiva entre TDC e imóveis tombados deixou de existir na cidade de São Paulo. Nesse sentido, não se pode afirmar que o Estatuto da Cidade tenha exercido impactos menos significativos no município pelo fato de este já usufruir de uma disciplina prévia da TDC, uma vez que a abertura do leque de finalidades autorizadoras e mesmo a possibilidade de doação do imóvel, ambos determinados pela lei federal, tiveram reflexo nas legislações municipais posteriores.

Apesar do aumento das finalidades autorizadoras no PDE-2002, os dados da Coordenadoria de Legislação de Uso e Ocupação do Solo da Prefeitura de São Paulo (DEUSO/PMSP) mostram que, ao longo dos doze anos de sua vigência, foram emitidas apenas 39 Declarações de Potencial Construtivo Passível de Transferência $^{5}$ e efetivadas 48 transferências de potencial construtivo. Dentre as declarações, apenas uma se voltava a uma finalidade diferente da preservação de imóveis tombados ${ }^{6}$. Tais dados nos permitem afirmar que, em que pese o fato de a TDC ter se mantido como um instrumento relevante de incentivo ao patrimônio histórico, no período de 2002 a 2014, ela produziu efeitos marginais como

\footnotetext{
4. A primeira revisão do marco regulatório da política urbana da cidade de São Paulo ocorreu como resultado da aprovação das Leis Municipais n⿳0 13.430/2002 e nº 13.885/2004, que instituíram, respectivamente, o Plano Diretor Estratégico e a Lei de Parcelamento, Uso e Ocupação do Solo.

5. O procedimento da TDC em São Paulo tem duas etapas: na primeira, é emitida a Declaração de Potencial Construtivo Passível de Transferência, na qual é registrada a área que poderá ser utilizada ou alienada; na segunda, é emitida a Certidão de Transferência de Potencial Construtivo, que registra a efetiva transferência.

6. A exceção é representada pelo imóvel São Paulo Golf Club, cuja finalidade é a preservação de área de interesse ambiental de propriedade particular.
} 
instrumento geral da política urbana municipal, considerando a baixa adesão do mercado às demais finalidades autorizadoras.

Esse cenário de utilização da TDC focada na proteção do patrimônio histórico se intensificou depois da disciplina estabelecida pelo PDE-2014: entre agosto de 2014 e dezembro de 2019, foram emitidas 217 declarações, das quais 213 para bens tombados (PERETTO, 2020) e somente quatro referentes a uma finalidade diversa da preservação cultural (todas correspondentes à área do Parque Augusta, conforme exposto adiante). Em termos de metros quadrados de potencial construtivo, isso representa um somatório de 1.911.668,21 $\mathrm{m}^{2}$ de potencial construtivo a ser vendido por esses bens particulares e disponibilizados no mercado. Quanto às transferências, foram efetivadas 67 até o final de dezembro de 2019, 58 delas de imóveis tombados, o que representa quase $87 \%$ do total de transferências de potencial construtivo efetivadas no mesmo período.

As hipóteses explicativas desse aumento mereceriam um estudo mais aprofundado, muito além do escopo deste artigo; no entanto, destacamos três aspectos que podem tê-lo influenciado: i) a fixação de um coeficiente de aproveitamento básico único para todo o município; ii) o ajuste nos valores de referência da OODC; e iii) a nova disciplina da TDC, que não prevê o desconto da área construída. Vejamos.

O PDE-2014 propôs um novo modelo de ordenação da transformação urbana no município, mediante a adoção de um conjunto de diretrizes, objetivos e estratégias, dentre as quais se inclui a fixação de um Coeficiente de Aproveitamento (CA) básico igual a 1 para toda a cidade, que pode ser alcançado gratuitamente por qualquer empreendimento. Para construir acima do CA básico, o empreendedor deve adquirir onerosamente o potencial construtivo adicional, respeitando o limite imposto pelo CA máximo, que não pode ser ultrapassado. A obtenção da área adicional pode ser feita com o pagamento da OODC, cujos valores foram definidos pela municipalidade no PDE-2014, ou pela compra de potencial construtivo por meio da TDC, cujo valor e venda se encontram sob o domínio de particulares.

Nesse sentido, a fixação de um CA básico único em todo o município equalizou a exigibilidade de aquisição, pelo particular, de potencial construtivo adicional. Foi, com efeito, um avanço em relação à legislação anterior, a qual estabelecia CAs básicos maiores e diversos, de acordo com a zona de uso, o que, além de tornar menos equilibrada a aquisição de potencial construtivo, viabilizava maiores construções sem a necessidade de aquisição de potencial construtivo adicional, ou seja, era possível empreender na cidade sem o pagamento de contrapartida financeira à prefeitura. 
Ao mesmo tempo, o PDE-2014 estabeleceu uma nova disciplina e ajustou os valores de referência para o cálculo da contrapartida financeira da OODC7, tendo em vista a necessidade de sua atualização para aproximá-los dos valores praticados pelo mercado. Com isso, as contrapartidas da OODC aumentaram, alteração que foi considerada excessiva pelos agentes privados. Esse novo contexto trouxe destaque à TDC como uma opção viável de aquisição de potencial construtivo pelo mercado, principalmente pelo fato de que o valor a ser pago pela área adquirida por intermédio da TDC é definido por uma negociação entre os particulares envolvidos (proprietários dos imóveis cedente e receptor de área adicional). Portanto, trata-se necessariamente de um valor inferior ao da OODC, uma vez que este é fixado pela prefeitura e não pode ser negociado. $O$ que se verificou foi uma ampliação do interesse do mercado na procura de imóveis dispostos a alienar seu potencial construtivo.

Em conjunção com o maior interesse do mercado pela TDC, a disciplina estabelecida pelo PDE-2014 para o cálculo do potencial construtivo transferível não prevê o desconto da área já construída nos imóveis autorizados a utilizar a TDC, diferentemente do que acontecia nas regras anteriores ${ }^{8}$. Isso serviu de incentivo ao aumento das solicitações de declarações, uma vez que a quantidade de potencial disponibilizada pelo proprietário ao uso ou alienação se tornou mais generosa. Possibilitou-se, dessa maneira, que imóveis tombados cuja construção já havia ultrapassado o potencial construtivo máximo do terreno pudessem usufruir desse recurso.

Diante desse cenário, fica mais fácil situar a TDC no contexto da política urbana proposta pelo PDE-2014 e entender que ela pode vir a cumprir, no longo prazo, um papel transformador no mercado de compra e venda de potencial construtivo (PERETTO; SANTORO; OKSMAN; MENDONÇA, 2018).

Atualmente, são seis as finalidades autorizadoras da TDC no município de São Paulo, parte delas concretizada por meio da modalidade que prevê a doação do imóvel à municipalidade e as demais, mediante a modalidade em que não há doação. Cada qual tem critérios, mecanismos e procedimentos diferentes, os quais veremos a seguir.

A modalidade de TDC em que não há doação de imóvel está circunscrita a duas finalidades: a de preservação de imóveis tombados e a de proteção de imóveis

\footnotetext{
7. O Quadro 14, anexo ao PDE-2014, traz os Valores de Terreno para fins de Outorga Onerosa, referência empregada para calcular o valor a ser pago na compra de potencial construtivo. Antes dele, utilizava-se o valor venal do imóvel, geralmente baixo e desatualizado.

8. Segundo o art. 125 do PDE-2014, o potencial transferível na modalidade sem doação é calculado pela multiplicação entre a área do terreno, o CA básico e um Fator de Incentivo (PCpt = At x CAbás. x Fi). Os Fatores de Incentivo foram definidos pelo art. 24 da Lei ${ }^{\circ}$ 16.402/16, variáveis conforme a área do terreno tombado.
} 
particulares de interesse ambiental. Assim, essa modalidade é permitida apenas aos imóveis demarcados como Zona Especial de Preservação Cultural (ZEPEC) ${ }^{9}$, especificamente Bens Imóveis Representativos (BIR) e Áreas de Proteção Cultural (APC) ${ }^{10}$, e como Zona Especial de Proteção Ambiental (ZEPAM) ${ }^{11}$.

Já a modalidade de TDC em que há doação de imóvel está voltada ao cumprimento de um leque maior de finalidades, casos da promoção da regularização fundiária, da provisão de Habitação de Interesse Social, da execução de melhoramentos viários voltados à implantação de corredores de ônibus e da implantação de Parques Planejados situados na Macrozona de Estruturação e Qualificação Urbana ${ }^{12}$.

Considerando o aumento de solicitações citado, o Poder Público, por meio da Legislação de Parcelamento, Uso e Ocupação do Solo ${ }^{13}$ (SÃO PAULO, 2016), complementou o regramento do PDE-2014 apenas para a finalidade de preservação de ZEPEC, estabelecendo uma disciplina mais robusta, caracterizada por limitações, obrigações e fatores de incentivo específicos, em uma tentativa de controlar o potencial construtivo disponibilizado no mercado particular com base em tais TDCs ${ }^{14}$. Entretanto, o que parece não ter sido previsto pelo Poder Público municipal foi a multiplicação de potencial construtivo proporcionada pela modalidade de TDC com doação para a implementação de parques.

\section{A TDC para a implantação de parques municipais}

Foi a partir do caso do Parque Augusta que, pela primeira vez, a Prefeitura de São Paulo foi provocada a fazer os cálculos referentes à TDC com doação para a implantação de Parques Municipais. Até então, todas as solicitações voltadas a essa modalidade enfrentavam as regras de uma regulamentação específica ${ }^{15}$ tão complexa e morosa, a ponto de represar todas as propostas de doação de áreas via TDC, ainda hoje, às fases mais iniciais de análise. Contudo, com a aprovação de um novo decreto de regulamentação em $2018^{16}$, o procedimento foi alterado, garantindo certa celeridade ao processo de análise das TDCs com doação. O caso do Parque Augusta foi analisado integralmente com base nesse decreto, o que lhe conferiu

\footnotetext{
9. Nos termos do art. 61 do PDE-2014, todo imóvel tombado é enquadrado como ZEPEC.

10. Para as quatro categoriais de ZEPEC existentes em São Paulo, ver o art. 63 do PDE-2014.

11. Ver art. 124 do PDE-2014.

12. Ver art. 127 do PDE-2014.

13. Lei Municipal $n^{\circ}$ 16.402, de 22 de março de 2016.

14. Ver art. 24 da LPUOS-2016.

15. Decreto Municipal $n^{\circ}$ 57.535/16, revogado pelo Decreto Municipal $n^{\circ}$ 58.289/18.

16. Decreto Municipal $n^{0} 58.289 / 18$.
} 
não apenas a rapidez necessária - visto que o acordo em sede de ação judicial dependia disso ${ }^{17}$-, como também o status de primeiro caso de utilização da TDC com doação para a implantação de um Parque Municipal.

\subsection{O caso do Parque Augusta}

O Parque Augusta é uma área de aproximadamente $24 \mathrm{mil} \mathrm{m}^{2}$, localizada em uma região nobre do município de São Paulo. Desde a década de 1970, encontra-se subutilizado, restando apenas alguns vestígios do antigo Colégio Des Oiseaux, demolido na década de $1960^{18}$.

Em 2013, foi realizada a venda da referida área a duas incorporadoras (Cyrela e Setin), interessadas na aprovação de um projeto de uso misto permitido pela Legislação de Uso e Ocupação do Solo vigente à época (LPUOS-2004). Protocolado o processo de licenciamento junto à prefeitura, tomou força um movimento existente havia anos e que reivindicava a destinação do terreno à implantação de um Parque Municipal. Esse movimento conseguiu garantir a demarcação da área como ZEPAM no processo de revisão da LPUOS e angariar o apoio de importantes entidades e órgãos públicos, como o Ministério Público do Estado de São Paulo, que protocolou uma ação judicial visando impedir a construção dos empreendimentos projetados pelas incorporadoras. Consolidou-se, assim, um imbróglio: ao mesmo tempo que Cyrela e Setin tinham o direito de protocolo assegurado pela legislação para construir o empreendimento projetado, havia uma pressão crescente da sociedade civil e de entidades representativas que lutavam por uma destinação diversa ao terreno. Começou, então, a ser desenhada uma tratativa de acordo entre Cyrela e Setin, Ministério Público, organizações da sociedade civil e Prefeitura Municipal de São Paulo, em que se previa a realização de TDC com doação de imóvel para viabilizar a implantação de Parque Municipal na área. Em contrapartida, as empresas assumiram o pagamento de $\mathrm{R} \$ 10$ milhões de reais, dos quais $60 \%$ deverão ser destinados às obras de implantação do parque e 40\% a um fundo para sua manutenção, para a implantação de um corredor verde conectando o parque à Praça Roosevelt e também para a reforma de escolas municipais de educação infantil.

A impressão inicial é de que o acordo não foi tão benéfico às incorporadoras, visto que, além do pagamento de $\mathrm{R} \$ 10$ milhões de reais, elas obtiveram baixa quantidade de metros quadrados transferíveis, correspondente apenas a $14 \%$ da área de seus terrenos. O benefício, de fato, não fica evidenciado por esses números;

17. Ação Civil Pública $n^{0}$ 1017163-55.2016.8.26.0053.

18. A quadra do Parque Augusta foi tombada em 2004 pelo Conselho Municipal de Preservação do Patrimônio Histórico, Cultural e Ambiental da Cidade de São Paulo (Conpresp) pela Resolução de Tombamento $n^{\circ} 23$. 
ele somente poderá ser auferido em sua integralidade se analisarmos as transferências efetivadas com base no potencial construtivo obtido via doação.

\subsection{Uma surpresa, diversas confirmações}

Para compreendermos os benefícios obtidos pelas construtoras, é preciso ter em mente que o procedimento da TDC é composto de duas etapas. Na primeira, o imóvel apto ao cumprimento de uma das finalidades da TDC solicita a emissão de uma Declaração de Potencial Construtivo Passível de Transferência, na qual será certificada a quantidade de potencial construtivo que o proprietário tem disponível para utilizar ou alienar. Para a modalidade de TDC com doação, o PDE-2014 estabeleceu como potencial transferível ( $\mathrm{PC} \mathrm{pt}^{\text {com doação) }}$ o resultado da multiplicação entre a área do terreno a ser doado (Atc), o CA máximo (CAmáx.) e um Fator de Incentivo (Fi), variável conforme a finalidade da doação ${ }^{19}$.

$$
\mathrm{PCpt}^{\mathrm{com} \text { doação }}=\text { Atc x CAmáx. } \mathrm{x} \text { Fi }
$$

No caso do Parque Augusta, foi certificado um potencial construtivo transferível de:

$$
3.322,62 \mathrm{~m}^{2}=23.733 \mathrm{~m}^{2} \times 0,1 \times 1,4
$$

Esse potencial total foi dividido em quatro declarações ${ }^{20}$, conforme evidenciado no Quadro 1.

\begin{tabular}{|c|c|c|}
\hline$N^{\circ}$ da declaração & Proprietário & $\begin{array}{c}\text { Potencial construtivo passível de } \\
\text { transferência }-\mathrm{PCpt}\left(\mathrm{m}^{2}\right)\end{array}$ \\
\hline 001 & Setin & 532,00 \\
\hline 002 & Cyrela & 532,00 \\
\hline 003 & Setin & $1.129,31$ \\
\hline 004 & Cyrela & $1.129,31$ \\
\hline \multicolumn{2}{|c|}{ Total } & $3.322,62$ \\
\hline
\end{tabular}

Quadro 1. Potencial construtivo certificado em cada uma das Declarações de Potencial Construtivo Passível de Transferência emitidas para o Parque Augusta

Fonte: DEUSO/PMSP, 2020.

Na segunda etapa, efetiva-se a transferência total ou parcial do potencial do imóvel cedente - calculado na primeira etapa - para um imóvel receptor.

19. Conforme artigo 127 do PDE-2014, os fatores de incentivo à doação são: 2,0 para melhoramentos viários para implantação de corredores de ônibus; 1,9 para construção de HIS; 0,8 para regularização fundiária e urbanização de áreas ocupadas por população de baixa renda; e 1,4 para implantação de parques.

20. Lembrando que a área do chamado Parque Augusta é formada por dois terrenos e que a propriedade de ambos era compartilhada pelas duas construtoras. Foi por essa razão que foram emitidas quatro declarações. 
Ressalta-se que a quantidade de metros quadrados que é retirada do imóvel cedente não é idêntica àquela recebida pelo imóvel receptor. Em outras palavras: não é porque o imóvel cedente aliena $300 \mathrm{~m}^{2}$ que o imóvel receptor necessariamente receberá esses $300 \mathrm{~m}^{2}$ - ele poderá receber uma quantidade maior ou menor, dependendo de sua localização. Isso acontece porque, na concepção da TDC do PDE-2014, o valor do metro quadrado de potencial construtivo varia de acordo com o local para o qual será transferido, levando em consideração a escala de investimento público voltado à implantação de infraestrutura já disponibilizada para o local.

Em razão disso, a transferência de potencial construtivo prescinde de um cálculo que age como uma fórmula de equivalência (BACELLAR, 2007) entre a área que é retirada do imóvel cedente e a área que chega até o imóvel receptor (PCr). Para tanto, multiplicam-se a quantidade de potencial construtivo a ser cedido (PCpt) e o valor do metro quadrado do imóvel cedente (VTcd); o resultado obtido deve ser dividido pelo produto da multiplicação do valor do metro quadrado de OODC do imóvel receptor (Cr) e o CA máximo do imóvel cedente ou doador (CAmáxcd) ${ }^{21}$ :

$$
\mathrm{PCr}=(\mathrm{PCpt} \times \mathrm{VTcd}) /(\mathrm{Cr} \times \mathrm{CAmáxcd})
$$

Nessa equação, temos que, quanto menor o valor do metro quadrado de OODC do terreno receptor, maior será o resultado do cálculo - ou seja, maior a quantidade de metros quadrados que o imóvel receptor receberá. Assim, a equação garante que a operação da TDC funcione em conformidade com a diferenciação dos valores do metro quadrado dos terrenos na cidade, fazendo com que os imóveis receptores localizados em áreas menos valorizadas da cidade recebam mais potencial construtivo do que aqueles situados em áreas mais nobres.

No caso do Parque Augusta, os benefícios das construtoras ficam evidentes com a efetivação das transferências do seu potencial construtivo: até julho de 2020, os dados da prefeitura mostram que nove transferências foram efetivadas tendo como base as quatro declarações do Parque Augusta. Esse número de transferências - bastante elevado, considerando o tempo transcorrido entre a emissão das declarações e o tempo médio de duração do procedimento para a efetivação de uma transferência - é explicado por uma particularidade do caso.

Destacamos anteriormente que foram emitidas quatro declarações correspondentes ao Parque Augusta, em função de ele ser composto de dois terrenos, cada qual com dois proprietários diferentes. Em virtude disso, uma mesma construtora pode efetivar transferências oriundas do potencial construtivo do Parque Augusta de maneira simultânea, sem precisar finalizar um processo de transferência para iniciar outro. Na prática, isso significa que o potencial oriundo do Parque Augusta

21. Cálculo disposto no art. 128 do PDE-2014. 
pode estar sendo transferido ao mesmo tempo para quatro empreendimentos diferentes. E, ao analisarmos os dados de cada uma dessas nove transferências, percebemos que, de fato, há grande disparidade entre o potencial construtivo cedido e o recebido em outro empreendimento.

O Quadro 2 revela que os 743,03 $\mathrm{m}^{2}$ até agora cedidos se transformaram em quase $56 \mathrm{mil} \mathrm{m}^{2}$ ao serem transferidos - uma multiplicação de mais de 75 vezes o potencial cedido.

\begin{tabular}{|c|c|c|c|c|c|}
\hline $\begin{array}{c}\mathbf{N}^{\circ} \text { da } \\
\text { declaração }\end{array}$ & Proprietário & $\begin{array}{c}\mathrm{PCpt} \text { inicial } \\
\left(\mathrm{m}^{2}\right)\end{array}$ & $\begin{array}{c}\mathrm{PCpt} \mathrm{já} \\
\text { cedido }\left(\mathrm{m}^{2}\right)\end{array}$ & $\begin{array}{c}\mathrm{N}^{\circ} \text { de } \\
\text { transferências } \\
\text { até jul. 2020 }\end{array}$ & $\begin{array}{c}\text { Total de área } \\
\text { construída em novos } \\
\text { edifícios }\left(\mathrm{m}^{2}\right)\end{array}$ \\
\hline 001 & Setin & 532,00 & 268,72 & 03 & $15.501,30$ \\
\hline 002 & Cyrela & 532,00 & 124,05 & 01 & $8.396,53$ \\
\hline 003 & Setin & $1.129,31$ & 113,02 & 02 & $10.159,44$ \\
\hline 004 & Cyrela & $1.129,31$ & 237,24 & 03 & $21.941,39$ \\
\hline
\end{tabular}

Quadro 2. Dados sobre as transferências efetivadas depois da emissão das Declarações de Potencial Construtivo Passível de Transferência para o Parque Augusta

Fonte: DEUSO/PMSP, 2020.

Se esse número parece exacerbado, é importante ressaltar que os distritos receptores do potencial construtivo oriundo do Parque Augusta são áreas cujo valor do metro quadrado, de acordo com o Quadro 14 anexo ao PDE-2014, é relativamente alto $^{22}$. Se as construtoras tivessem optado por transferir o potencial construtivo original para distritos com valor de metro quadrado mais baixo, como é o caso da Vila Prudente, a área construída recebida poderia ultrapassar cem vezes o valor do potencial original, ante a fórmula de equivalência, já demonstrada.

Diante de tais cifras, torna-se compreensível a magnitude do benefício que o acordo judicial garantiu às incorporadoras proprietárias do terreno do Parque Augusta. Pois, se 3.322,62 $\mathrm{m}^{2}$ parecem, a princípio, uma quantidade pequena de potencial para ser alienado, o que fica evidente após as transferências efetivadas é a capacidade de esse potencial se multiplicar enormemente, resultando em um aumento do estoque de potencial construtivo controlado pelos agentes privados, bem como no surgimento de uma fonte pecuniária rentável. Para ilustrarmos melhor essa grandeza, de acordo com as estimativas realizadas pelo jornal $A$ Folha de S.Paulo, o potencial construtivo recebido pelas incorporadoras foi avaliado em $\mathrm{R} \$ 205$ milhões de reais ${ }^{23}$.

22. Os distritos foram: Jardim Paulista, Moema, Perdizes, Pinheiros, Santo Amaro e Vila Mariana.

23. Conforme notícia veiculada pelo jornal A Folha de S.Paulo. Disponível em: https://www1.folha.uol. com.br/cotidiano/2018/11/empreiteiras-podem-lucrar-ate-r-95-milhoes-com-acordo-do-parque-augusta. shtml. Acesso em: 10 ago. 2020. 
Se a certeza quanto aos benefícios das incorporadoras se tornou evidente, paira, ainda, um questionamento sobre o alcance da multiplicação verificada: seria ela exclusiva do Parque Augusta, pelo fato de ele estar localizado em uma área nobre da cidade com valor de potencial construtivo alto ou essa multiplicação se reproduziria em outros episódios de TDC?

Para responder a tais questionamentos, foram efetuadas simulações. Na primeira delas, focamos nas TDCs com doação para a implantação de Parques Municipais. Reportamo-nos ao Quadro 7 anexo ao PDE-2014 e selecionamos todos os Parques Planejados que podem transferir potencial construtivo mediante doação, ou seja, aqueles localizados na Macrozona de Estruturação e Qualificação Urbana ${ }^{24}$, classificados como "urbanos" ${ }^{25}$ e de propriedade privada ${ }^{26}$ (Figura 1).

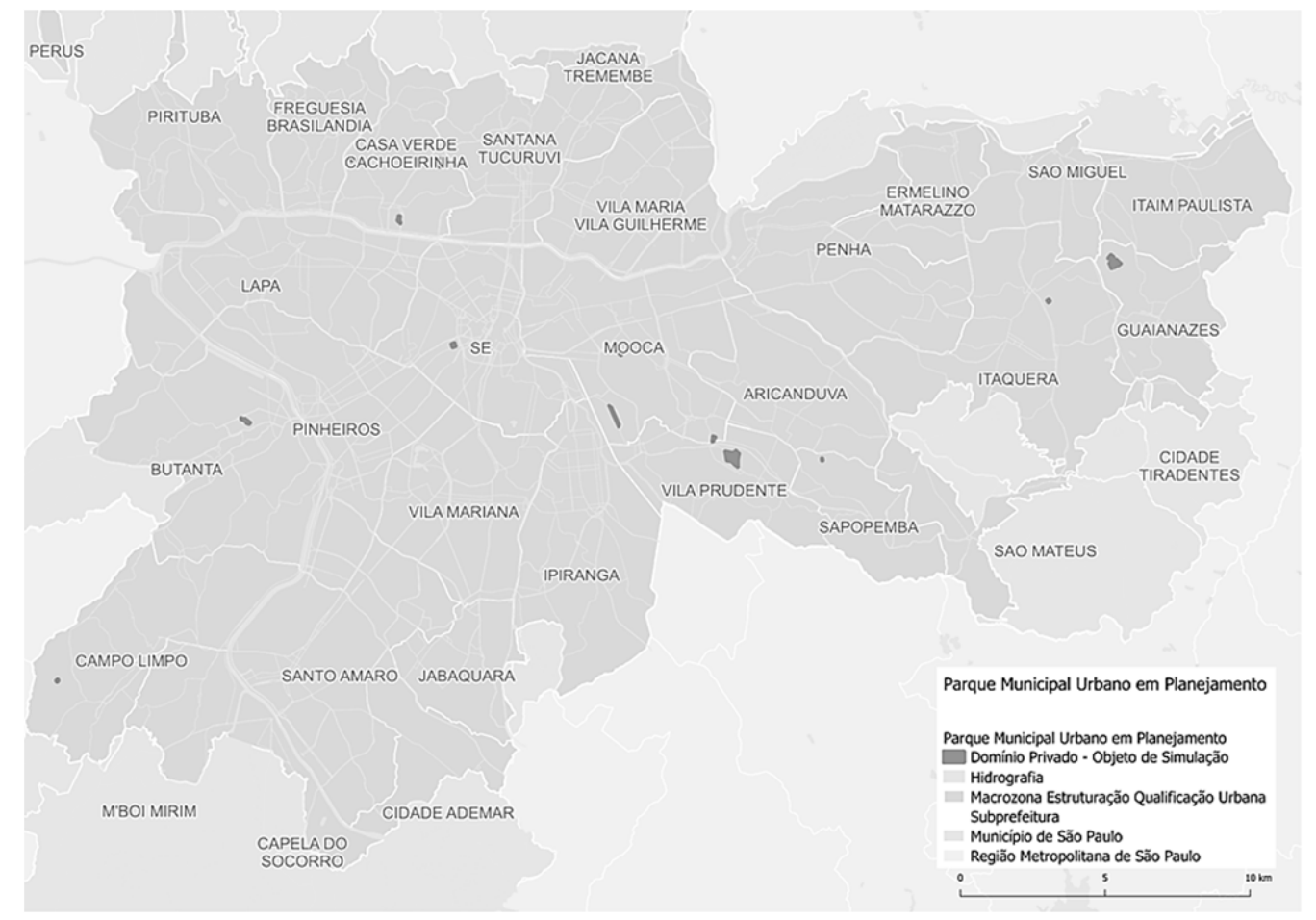

Figura 1. Imóveis demarcados como Parques Municipais Urbanos em Planejamento analisados neste artigo

Fonte: Elaboração das autoras, 2020.

24. Conforme determina o art. 126, IV do PDE-2014.

25. Os Parques Planejados classificados como "lineares” não foram incorporados na simulação devido à impossibilidade de precisar sua área de terreno. De acordo com o art. 273, §2 do PDE, os perímetros de tais parques apenas são definitivamente desenhados quando se tem em mãos o respectivo projeto.

26. Os imóveis de domínio público não utilizariam a TDC com doação, já que a municipalidade é titular deles. 
Ao todo, foram selecionados treze Parques Planejados. Primeiramente, calculamos os valores de potencial construtivo passível de transferência (PCpt) correspondente a cada um deles (Quadro 3). Ato contínuo, aplicamos a todos a fórmula de equivalência em cenários hipotéticos. Para tais cenários, selecionamos as subprefeituras da Vila Mariana e de Vila Prudente como referências comparativas, por serem localidades nas quais o mercado imobiliário tem atuado por meio da compra de potencial construtivo adicional via TDC.

\begin{tabular}{|c|c|c|c|c|c|c|}
\hline \multirow[b]{2}{*}{$\begin{array}{l}\text { Nome do } \\
\text { parque }\end{array}$} & \multirow[b]{2}{*}{$\begin{array}{l}\text { Endereço de } \\
\text { referência }\end{array}$} & \multirow[b]{2}{*}{ Subprefeitura } & \multirow[b]{2}{*}{ Setor-quadra } & $\operatorname{ATc}\left(m^{2}\right)$ & VTcd (R\$) & PCpt $\left(m^{2}\right)$ \\
\hline & & & & $\begin{array}{l}\text { Área do } \\
\text { terreno } \\
\text { do imóvel } \\
\text { cedente }\end{array}$ & $\begin{array}{l}\text { Valor do } \mathrm{m}^{2} \\
\text { do imóvel } \\
\text { cedente }\end{array}$ & $\begin{array}{l}\text { Potencial } \\
\text { Construtivo } \\
\text { Transferível }\end{array}$ \\
\hline Da Fonte & R. Santanésia & Butantã & 082402 & $35 \cdot 636,71$ & $1.557,00$ & $4.989,14$ \\
\hline $\begin{array}{l}\text { Jardim } \\
\text { Macedônia }\end{array}$ & $\begin{array}{l}\text { R. Emílio } \\
\text { Conesa }\end{array}$ & Campo Limpo & 184246 & $9.550,65$ & 678,00 & $1.337,09$ \\
\hline $\begin{array}{l}\text { Mata da Rua } \\
\text { dos Rodrigues }\end{array}$ & R. Luci & $\begin{array}{l}\text { Casa Verde/ } \\
\text { Cachoeirinha }\end{array}$ & 076293 & $8.578,80$ & $1.239,00$ & $1.201,03$ \\
\hline $\begin{array}{l}\text { Clube } \\
\text { Matarazzo }\end{array}$ & R. Samaritá & $\begin{array}{l}\text { Casa Verde/ } \\
\text { Cachoeirinha }\end{array}$ & 306079 & $26.690,46$ & 792,00 & $3.736,66$ \\
\hline $\begin{array}{l}\text { Vila Ester (Sítio } \\
\text { Niasi Chofi) }\end{array}$ & $\begin{array}{l}\text { R. Gregório } \\
\text { dos Santos }\end{array}$ & $\begin{array}{l}\text { Casa Verde/ } \\
\text { Cachoeirinha }\end{array}$ & 075025 & $61.962,80$ & 826,00 & $8.674,79$ \\
\hline $\begin{array}{l}\text { Lajeado- } \\
\text { Santa Etelvina }\end{array}$ & $\begin{array}{l}\text { R. Santa } \\
\text { Etelvina }\end{array}$ & Guaianases & 138370 & $110.984,15$ & 819,00 & $1.5537,78$ \\
\hline $\begin{array}{l}\text { Sabbado } \\
\text { D'Ângelo }\end{array}$ & $\begin{array}{l}\text { R. Narciso } \\
\text { Araújo }\end{array}$ & Itaquera & 114056 & $11.065,04$ & 592,00 & $1.549,11$ \\
\hline $\begin{array}{l}\text { Padre } \\
\text { Benedito Maria } \\
\text { Cardoso }\end{array}$ & $\begin{array}{l}\text { R. Padre } \\
\text { Benedito }\end{array}$ & Mooca & 031062 & $4.675,15$ & $1.816,00$ & 654,52 \\
\hline $\begin{array}{l}\text { Avenida Vila } \\
\text { Ema }\end{array}$ & Av. Vila Ema & Mooca & 102099 & $17.230,79$ & $1.489,00$ & $2.412,31$ \\
\hline $\begin{array}{l}\text { Parque da } \\
\text { Mooca }\end{array}$ & R. Dianópolis & Mooca & 032110 & $51.232,57$ & $1.133,00$ & $7.172,56$ \\
\hline $\begin{array}{l}\text { Campo da } \\
\text { Primavera }\end{array}$ & $\begin{array}{l}\text { Av. Pero de } \\
\text { Góis }\end{array}$ & Sapopemba & 117121 & $6.781,23$ & 737,00 & 949,37 \\
\hline Augusta & R. Caio Prado & Sé & 010014 & $23.733,00$ & $6.183,00$ & $3 \cdot 322,62$ \\
\hline $\begin{array}{l}\text { São Lucas/ } \\
\text { Linhas Corrente }\end{array}$ & R. Ribeirópolis & Vila Prudente & 118342 & $180.355,13$ & $1.237,00$ & $25 \cdot 249,72$ \\
\hline
\end{tabular}

Quadro 3. Parques Planejados que podem transferir potencial construtivo mediante doação Fonte: Elaboração das autoras, 2020, conforme Mapa 5 e Quadro 7 do PDE-2014.

A escolha dessas subprefeituras também considerou o fato de serem regiões que apresentam valores distintos de metro quadrado, tendo em vista que a primeira integra o quadrante sudoeste paulistano (VILLAÇA, 2011), onde o preço da 
terra é mais valorizado, enquanto a segunda, por mais que faça parte da recente atuação do mercado, ainda não passou por tal processo de valorização da terra. Além disso, essas subprefeituras inserem-se em diferentes macroáreas definidas pelo PDE-2014, o que significa que, para cada uma delas, foram previstas diferentes estratégias de ordenamento do solo, o que também influencia no cálculo da TDC.

Ademais, para fins de construção do cenário hipotético, estabelecemos como imóveis receptores “tipo", terrenos com área total de $1.500 \mathrm{~m}^{2}$, localizados nas subprefeituras citadas e demarcados como Zona Eixo de Estruturação da Transformação Urbana (ZEU), por ser a zona mais propensa ao adensamento. Neles seriam construídos empreendimentos de uso residencial compostos de unidades com área entre $51 \mathrm{~m}^{2}$ e $70 \mathrm{~m}^{2}$ e que chegariam ao limite do CA máximo permitido - o que demandaria $4.500 \mathrm{~m}^{2}$ de potencial construtivo adicional ${ }^{27}$ para cada edificação. Os parâmetros utilizados nas simulações para os imóveis receptores fictícios estão sistematizados no Quadro 4.

\begin{tabular}{|c|c|c|c|c|c|}
\hline & CAmáx. & VTr & Fs & $\mathrm{Fp}$ & $\mathrm{Cr}$ \\
\hline $\begin{array}{l}\text { Imóvel } \\
\text { receptor }\end{array}$ & $\begin{array}{l}\text { Coeficiente } \\
\text { máximo na } \\
\text { ZEU }\end{array}$ & $\begin{array}{c}\text { Valor do } \\
\text { imóvel receptor } \\
\text { Quadro } 14\end{array}$ & $\begin{array}{c}\text { Fator de } \\
\text { interesse social } \\
\text { Quadro 5(a) }\end{array}$ & $\begin{array}{c}\text { Fator de } \\
\text { planejamento } \\
\text { Quadro 6(b) }\end{array}$ & $\begin{array}{c}\text { Valor da } \\
\text { contrapartida da } \\
\text { outorga onerosa } \\
\left(\mathrm{R} \$ / \mathrm{m}^{2}\right)\end{array}$ \\
\hline Vila Mariana & 4,00 & $6.325,00$ & 0,9 & 0,7 & 996,19 \\
\hline Vila Prudente & 4,00 & $2.695,00$ & 0,9 & 0,6 & 363,83 \\
\hline
\end{tabular}

Quadro 4. Dados sobre as transferências efetivadas depois da emissão das Declarações de Potencial Construtivo Passível de Transferência para o Parque Augusta

Notas: (a) Fator de interesse social para "Habitação com área de $51 \mathrm{~m}^{2}$ até $70 \mathrm{~m}^{2 \prime}$ é igual a 0,9;

(b) Fator de planejamento conforme localização da macroárea do imóvel.

Fonte: Elaboração das autoras, 2020.

O que podemos observar no Quadro 5 é que o aumento desproporcional de potencial construtivo não se restringe ao Parque Augusta. Os resultados demonstram uma tendência entre os casos de TDC com doação para a implantação de Parques Municipais. Sem dúvida, o Parque Augusta ainda é o exemplo mais expressivo da multiplicação desproporcional de valores de potencial construtivo (Figura 2), por ostentar uma possibilidade de construções muito elevada para cada subprefeitura e assim deter considerável capacidade de abastecimento do limite do CA máximo de empreendimentos residenciais.

27. Para o terreno receptor com área de $1.500 \mathrm{~m}^{2} \mathrm{em}$ ZEU, zona na qual o CA máximo é igual a 4, é possível a construção de até 6 mil m² de área computável. Como o CA básico é 1, pode-se construir gratuitamente até $1.500 \mathrm{~m}^{2}$, havendo a necessidade de pagamento de OODC ou da TDC para os demais $4.500 \mathrm{~m}^{2}$. 


\begin{tabular}{|c|c|c|c|c|c|}
\hline \multicolumn{2}{|c|}{$\begin{array}{c}\text { Imóvel doador para } \\
\text { implantação de parque (a) }\end{array}$} & \multicolumn{2}{|c|}{$\begin{array}{l}\text { Imóvel receptor } \\
\text { Vila Mariana (b) }\end{array}$} & \multicolumn{2}{|c|}{$\begin{array}{l}\text { Imóvel receptor } \\
\text { Vila Prudente (b) }\end{array}$} \\
\hline $\begin{array}{l}\text { Nome, } \\
\text { Subprefeitura }\end{array}$ & $\begin{array}{c}\text { Potencial } \\
\text { transferível } \\
(\mathrm{PCpt})\left(\mathrm{m}^{2}\right)\end{array}$ & $\begin{array}{c}\text { Potencial a ser } \\
\text { recebido }(\mathrm{PCr}) \\
\left(\mathrm{m}^{2}\right)(\mathrm{c})\end{array}$ & $\begin{array}{c}\mathrm{N}^{\circ} \text { de } \\
\text { empreendedores } \\
\text { receptores }(\mathrm{d})\end{array}$ & $\begin{array}{c}\text { Potencial a ser } \\
\text { recebido }(\mathrm{PCr}) \\
\left(\mathrm{m}^{2}\right)(\mathrm{c})\end{array}$ & $\begin{array}{c}\mathrm{N}^{\circ} \text { de } \\
\text { empreendedores } \\
\text { receptores (d) }\end{array}$ \\
\hline Da Fonte, Butantã & $4.989,14$ & $77.978,19$ & 17,33 & $213.511,72$ & 47,45 \\
\hline $\begin{array}{l}\text { Jardim Macedônia, } \\
\text { Campo Limpo }\end{array}$ & $1.337,09$ & $9.100,17$ & 2,02 & $24.917,14$ & 5,54 \\
\hline $\begin{array}{l}\text { Mata da Rua dos } \\
\text { Rodrigues, Casa } \\
\text { Verde-Cachoeirinha }\end{array}$ & $1.201,03$ & $14.937,74$ & 3,32 & $40.900,95$ & 9,09 \\
\hline $\begin{array}{l}\text { Clube Matarazzo, } \\
\text { Casa Verde-Ca- } \\
\text { choeirinha }\end{array}$ & $3.736,66$ & $29.707,64$ & 6,6 & $81.342,35$ & 18,08 \\
\hline $\begin{array}{l}\text { Vila Ester (Niasi } \\
\text { Chofi), Casa Verde- } \\
\text {-Cachoeirinha }\end{array}$ & $8.674,79$ & $71.928,01$ & 15,98 & $196.945,73$ & 43,77 \\
\hline $\begin{array}{l}\text { Lajeado-Santa Etel- } \\
\text { vina, Guaianases }\end{array}$ & $15.537,78$ & $127.741,44$ & 28,39 & $349.768,23$ & 77,73 \\
\hline $\begin{array}{l}\text { Sabbado D'Ângelo, } \\
\text { Itaquera }\end{array}$ & $1.549,11$ & $9.205,80$ & 2,05 & $25.206,36$ & 5,6 \\
\hline $\begin{array}{l}\text { Padre Benedito } \\
\text { Maria Cardoso, } \\
\text { Mooca }\end{array}$ & 654,52 & $11.931,59$ & 2,65 & $32.669,83$ & 7,26 \\
\hline $\begin{array}{l}\text { Avenida Vila Ema, } \\
\text { Mooca }\end{array}$ & $2.412,31$ & $36.056,77$ & 8,01 & $98.726,87$ & 21,94 \\
\hline $\begin{array}{l}\text { Parque da Mooca, } \\
\text { Mooca }\end{array}$ & $7.172,56$ & $81.576,11$ & 18,13 & $223 \cdot 363,16$ & 49,64 \\
\hline $\begin{array}{l}\text { Campo da Primave- } \\
\text { ra, Sapopemba }\end{array}$ & 949,37 & $7.023,65$ & 1,56 & $19.231,42$ & 4,27 \\
\hline Augusta, Sé & $3 \cdot 322,62$ & $206.223,80$ & 45,83 & $564.660,47$ & 125,48 \\
\hline $\begin{array}{l}\text { São Lucas/Linhas } \\
\text { Corrente, Vila } \\
\text { Prudente }\end{array}$ & $25 \cdot 249,72$ & $313.534,36$ & 69,67 & $858.486,95$ & 190,77 \\
\hline Total & $76.786,70$ & $996.945,27$ & 221,54 & $2.729 \cdot 731,18$ & 606,62 \\
\hline
\end{tabular}

Quadro 5. Simulação de TDC dos Parques Municipais Urbanos Planejados na Macrozona de Estruturação e Qualificação Urbana

Notas: (a) Ver Quadro 3 deste artigo; (b) Imóvel com área de terreno total de $1.500 \mathrm{~m}^{2}$ localizado em ZEU; (c) Conforme art. 128 do PDE-2014; (d) Considerando um empreendimento com 6 mil m² de área construída computável total.

Fonte: Elaboração das autoras, 2020.

Nesse sentido, entende-se que, para o proprietário de uma área passível de ser doada para a implantação de um parque municipal, mais vale a localização do imóvel no qual será implantado o parque do que a quantidade de metros quadrados transferíveis atribuída à área. Basta verificar que o Parque do Lajeado-Santa Etelvina tem mais de quatro vezes o potencial transferível do Parque Augusta, o 
qual, ao ser recebido na Vila Mariana, por exemplo, não produz uma multiplicação tão expressiva quanto a daquele parque, uma vez que o valor do metro quadrado atribuído ao terreno do Lajeado-Santa Etelvina é muito inferior àquele relativo aos do Parque Augusta.

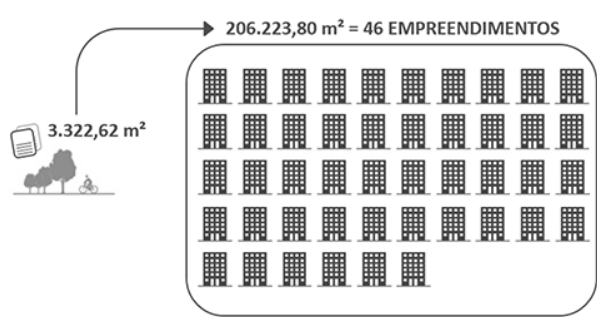

VILA MARIANA

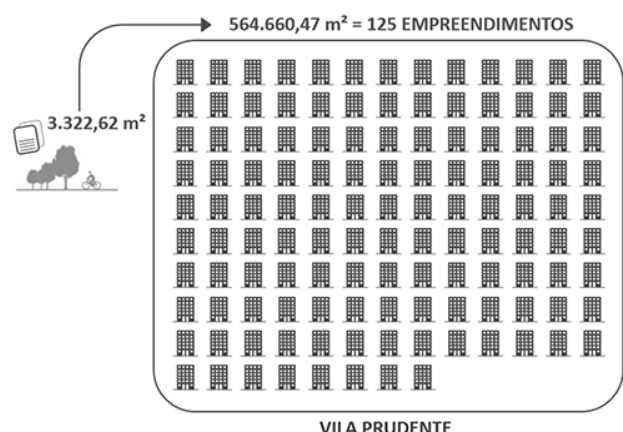

VILA PRUDENTE

Figura 2. Destaque para a multiplicação de potencial construtivo obtida com a simulação realizada com os dados referentes às Declarações do Parque Augusta

Fonte: Elaboração das autoras, 2020.

Tais resultados, contudo, não se reproduzem em nenhuma outra modalidade ou finalidade da TDC que não aquela que envolve a doação de imóvel para a implantação de Parques Municipais. Para fins de comparação, ao utilizarmos a mesma metodologia mencionada, porém vinculada às finalidades de TDC sem doação, temos que, no caso hipotético de um imóvel tombado ou de um imóvel privado de interesse ambiental detentor de um mesmo montante de potencial transferível do Parque Augusta, 3.322,62 m², o potencial equivalente a ser construído na Vila Mariana seria de $5 \cdot 155,60 \mathrm{~m}^{2}$, ao passo que, na Vila Prudente, seria de 14.116,51 $\mathrm{m}^{2}$ (Figura 3).
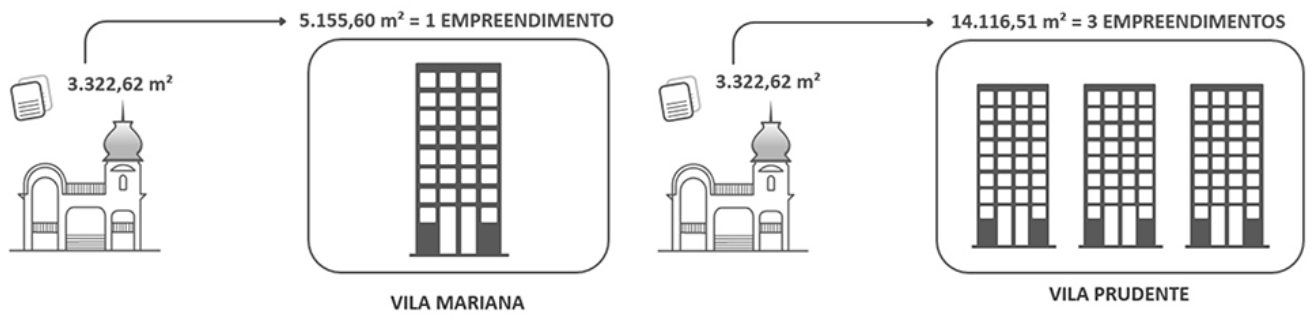

Figura 3. Resultado da simulação para a TDC de ZEPEC sem doação Fonte: Elaboração das autoras, 2020.

Da mesma forma, ao simularmos uma transferência de potencial construtivo vinculada à finalidade de implantação de melhoramentos viários, os mesmos 
3.322,62 $\mathrm{m}^{2}$ de potencial construtivo transferível equivaleriam a 10.311,19 $\mathrm{m}^{2}$ na Subprefeitura da Vila Mariana e 28.233,02 $\mathrm{m}^{2}$ na de Vila Prudente ${ }^{28}$ (Quadro 6). Portanto, ainda que seja observado um aumento de metro quadrado com as transferências nas modalidades citadas, este não se compara com o aumento desproporcional observado no caso das TDCs com doação para a implantação de parques municipais.

\begin{tabular}{|c|c|c|c|}
\hline Modalidade da TDC & $\begin{array}{c}\text { Potencial } \\
\text { transferível }\left(\mathrm{m}^{2}\right)\end{array}$ & $\begin{array}{c}\text { Potencial equivalente } \\
\text { na Vila Mariana }\left(\mathrm{m}^{2}\right)\end{array}$ & $\begin{array}{c}\text { Potencial equivalente } \\
\text { na Vila Prudente }\left(\mathrm{m}^{2}\right)\end{array}$ \\
\hline ZEPAM com doação & $3.322,62$ & $\mathbf{2 0 6 . 2 2 3 , 8 0}$ & $\mathbf{5 6 4 . 6 6 0 , 4 7}$ \\
\hline ZEPEC-BIR sem doação & $3.322,62$ & $5.155,60$ & $14.116,51$ \\
\hline ZEPAM sem doação & $3.322,62$ & $5.155,60$ & $14.116,51$ \\
\hline Melhoramento viário & $3.322,62$ & $10.311,19$ & $28.233,02$ \\
\hline
\end{tabular}

Quadro 6. Sistematização do potencial construtivo equivalente nas diferentes modalidades de TDC Fonte: Elaboração das autoras, 2020.

Disso, depreende-se que é significativa a disparidade de valores de potencial construtivo recebido pelos imóveis receptores, a depender da modalidade de TDC. Essa disparidade fica ainda mais realçada ao considerarmos que o cálculo da fórmula da equivalência é único e independe da modalidade ou finalidade a ser atingida. O que explicaria, então, a distorção observada?

A explicação para que a ocorrência desse fenômeno se restrinja a essa modalidade e finalidade da TDC é puramente matemática: assim como o valor do metro quadrado de OODC, o valor do CA máximo do imóvel cedente também é inversamente proporcional ao valor do potencial recebido pelo imóvel receptor. E aí reside a anomalia da TDC com doação para parques: pois, se o PDE-2014 determina que todos os Parques Planejados são ZEPAM e se toda ZEPAM tem CA máximo 0,1, então todas as TDCs que envolverem doação para a implantação de Parques Municipais vão resultar em uma multiplicação significativa do potencial recebido pelo imóvel receptor, ainda que a quantidade de potencial transferível do imóvel cedente não seja tão grande.

Isso não ocorre na modalidade de TDC sem doação, tendo em vista que o legislador teve o cuidado de fixar, arbitrariamente, a utilização de CA máximo igual a 4 na realização da fórmula de equivalência ${ }^{29}$. Assim, tanto para os imóveis particulares em ZEPAM como para os imóveis tombados, o CA máximo da fórmula de

28. Considerando que o imóvel a ser doado esteja inserido em uma Zona de Centralidade, cujo CA máximo é 2, nos termos do Quadro 3 anexo à LPUOS-2016.

29. Ver $\S 1^{0}$ art. 128 do PDE-2014. 
equivalência será sempre 4, independentemente do zoneamento demarcado sobre o imóvel. Nenhuma das demais finalidades - como a regularização fundiária, a construção de HIS ou a implantação de melhoramentos viários - pode ser implantada em terreno cujo zoneamento seja ZEPAM, em virtude das restrições ambientais dessa zona. À vista disso e considerando, ainda, que somente as ZEPAM têm CA máximo menor do que 1 nos termos da LPUOS-2016, o fenômeno não deve se repetir em nenhum outro caso senão os de TDC com doação para a implantação de parques.

Diante disso, questionamos: a multiplicação ora tratada reflete uma intenção do legislador? Seria ela uma forma de incentivo à finalidade de implantação de Parques Municipais - correspondendo aos objetivos do PDE-2014 quanto à melhoria da qualidade ambiental da cidade -, ou seria uma anomalia acidental? Mais do que buscar as respostas para tais questionamentos, entende-se que o fundamental é compreender os efeitos que a multiplicação desproporcional pode ocasionar no território.

Um efeito guarda relação com o fortalecimento de um mercado privado de compra e venda de potencial construtivo adicional. É presumível que, quando da formulação da disciplina da TDC no PDE-2014, o Poder Público tivesse ciência de que o aumento da efetivação do instrumento acarretaria uma nova fonte de aquisição de potencial adicional, de maneira que a estruturação do mercado privado de compra e venda de potencial construtivo adicional em si não é algo inesperado. Entretanto, o que foi possível observar ao longo do presente artigo é que a modalidade da TDC com doação de terreno para a implantação de Parque Municipal apresenta uma anomalia, ainda que puramente matemática, que induz ao crescimento desproporcional do potencial construtivo privado. Esse crescimento pode ser um fator de fortalecimento do mercado em questão, que atualmente opera mediante uma regulamentação majoritariamente privatista.

Dessa situação, decorrem dois efeitos. Um deles se refere ao fortalecimento de agentes privados detentores do conhecimento para intermediar o mercado privado ascendente, transformando-se, assim, em mediadores profissionais da TDC. Vale ressaltar que muitos desses agentes oferecem seus serviços aos proprietários dos imóveis aptos à TDC que até então desconheciam o instrumento e seus benefícios, o que pode ser positivo - desde que os proprietários utilizem o valor recebido via TDC para cumprir as finalidades do instrumento.

O segundo efeito diretamente associado ao fortalecimento do mercado privado de potencial construtivo adicional consiste na diminuição na arrecadação dos valores da OODC. A recente intensificação do uso da TDC coloca essa 
ferramenta na posição de concorrente daquela, podendo impactar significativamente a arrecadação da OODC e, em consequência, o abastecimento do Fundo de Desenvolvimento Urbano (FUNDURB). Esse fundo, disciplinado também pelo PDE2014, garante a execução de diversas ações prioritárias, como a compra de terrenos para a construção de HIS. A magnitude desse efeito, entretanto, somente poderá ser avaliada com o tempo e a evolução da TDC no município.

Adicionalmente, outro efeito diz respeito a um possível aumento de requerimentos de doações de imóveis à prefeitura para a instalação de parques, uma vez que a TDC permite que o proprietário do imóvel se livre de um terreno pouco aproveitável (em vista dos parâmetros restritos de uso e ocupação em ZEPAM) e receba, ao mesmo tempo, em contrapartida, um potencial que poderá render muito mais do que o próprio gozo do terreno doado. Efeito análogo a esse já vem sendo observado em relação aos imóveis tombados, cujos proprietários, que antes eram contra o tombamento, hoje entendem os benefícios aferidos pelo instituto quando operado em conjunto com a TDC, de modo que já estão sendo aventados pedidos de tombamento de imóveis com vistas, prioritariamente, à posterior utilização dos benefícios da TDC. No caso dos parques, ainda que o aumento de parques municipais atenda ao interesse público e às diretrizes do PDE-2014, é preciso considerar que a prefeitura segue contando com uma estrutura limitada de gestão e fiscalização das suas áreas públicas, de forma que o recebimento de doações deve ser feito de maneira correspondente às suas capacidades.

Nesse sentido, a regulamentação vigente para a TDC com doação no município de São Paulo teve o cuidado de estabelecer um rigoroso procedimento para a efetivação dessa modalidade, em virtude da necessidade de análise e ateste do interesse da municipalidade no recebimento das áreas em doação. Tal rigor é de fundamental importância para respaldar a municipalidade, sobretudo caso ela negue a oferta de doação - já que, como dito, em que pese a importância de o Poder Público constituir um banco de terras próprio e garantir o cumprimento das finalidades da TDC, não é desejável que qualquer terreno particular seja facilmente repassado à prefeitura, sob o risco de esta se tornar depositária de terrenos “micados”. Sem dúvida, os procedimentos mencionados são importantes, porém insuficientes por não imporem limites ou restrições à TDC em si.

O caso das TDCs de imóveis tombados é uma exceção: à vista do aumento das solicitações de declarações no período subsequente ao PDE-2014, o Poder Público estabeleceu novos regramentos, com o objetivo de promover equilíbrio e compensação entre os instrumentos da TDC e da OODC. A regulamentação, reitera-se, voltou-se exclusivamente aos casos de transferências efetuadas envolvendo 
imóveis tombados ${ }^{30}$. À parte desta e da trava imposta às TDCs sem doação originadas de imóveis com grande potencial transferível ${ }^{31}$, não há hoje nenhum regramento que preveja outra limitação às demais finalidades e modalidades da TDC.

Por fim, é preciso fazer uma ponderação: apesar de todos os efeitos ora elencados, atualmente o universo de imóveis autorizados à TDC com doação para a implantação de Parques Municipais é bastante restrito. Isso porque, além de esse universo se referir a um número pequeno de imóveis, sua expansão só pode ser realizada por meio da aprovação de uma legislação que altere o rol estabelecido pelo PDE-2014. Nesse ponto, trata-se de uma modalidade muito diferente daquela voltada à preservação de imóveis tombados, significativa em termos numéricos e também facilmente expandida, já que o tombamento é um instituto replicável a vários imóveis.

Por essas razões, entendemos que as reflexões apresentadas neste artigo cumprem a função de introduzir o debate da TDC e dos seus potenciais efeitos, visando ao desenvolvimento e ao aprimoramento da aplicação e da regulamentação do instrumento nos municípios.

\section{Conclusão}

No presente artigo, nossa proposta foi analisar a TDC com doação de imóveis para a implantação de Parques Municipais, em vista da multiplicação desproporcional de potencial construtivo observada em relação ao Parque Augusta. Do que pudemos apreender, tem-se nesse caso uma característica da referida modalidade e finalidade, consequência de uma distorção matemática provavelmente não prevista pelo Poder Público.

Foram elencados, então, alguns efeitos que poderiam resultar da anomalia encontrada, os quais se resumem i) ao fortalecimento do mercado privado de compra e venda de potencial construtivo adicional; ii) à maior estruturação de atores privados profissionalizados nas operações da TDC; iii) ao impacto na arrecadação da OODC e, consequentemente, do FUNDURB; iv) ao aumento das solicitações à municipalidade de doações de áreas para implantação de parques sem que haja um aprimoramento do sistema de gestão e fiscalização dos imóveis públicos municipais.

\footnotetext{
30. Ver $\S 5^{\circ}$, art. 24 da LPUOS-2016. A compra via TDC de potencial construtivo adicional de imóveis enquadrados como ZEPEC fica limitada à $5 \%$ do valor arrecadado pelo FUNDURB nos doze meses anteriores ao mês do requerimento da transferência.

31. Ver $\S 3^{\circ}$, art. 124 do PDE-2014: “Quando o potencial construtivo passível de transferência [nos casos em que não há a doação] ultrapassar $50.000 \mathrm{~m}^{2}$, a transferência do que exceder este limite se dará de forma gradativa em dez parcelas anuais, incluindo as declarações já emitidas anteriormente à publicação desta lei”.
} 
Tais efeitos, no entanto, são apenas projeções do que pode acontecer; fatores externos e inesperados podem acarretar efeitos imprevisíveis, de maneira que nossa proposta aqui não é fazer nenhum tipo de previsão. Contudo, entendemos que o debate sobre as consequências esperadas e inesperadas do planejamento urbano é fundamental para o desenvolvimento das experiências futuras.

\section{Referências}

BACELLAR, I. Transferência do direito de construir: questões e conflitos na aplicação do instrumento do Estatuto da Cidade. 2007. Dissertação (Mestrado) - Programa de Pós-graduação em Arquitetura e Urbanismo, Universidade Federal Fluminense, Niterói, 2007.

BRASIL. Lei $n^{\circ} 10.257$ de 10 de julho de 2001. Regulamenta os artigos 182 e 183 da Constituição Federal, estabelece diretrizes gerais da política urbana e dá outras providências. Diário Oficial da União: Brasília, DF, 2001. Disponível em: http://www.planalto.gov.br/ccivil_03/ LEIS/LEIS_2001/L10257.htm. Acesso em: 10 ago. 2020.

PERETTO, F. T. Transferência do Direito de Construir em São Paulo: concepção e gestão no contexto do mercado de direitos de construir. 2020. Dissertação (Mestrado) - Faculdade de Arquitetura e Urbanismo, Universidade de São Paulo, São Paulo, 2020.

. A Transferência do Direito de Construir na conservação dos imóveis tombados do município de São Paulo. In: SIMPÓSIO CIENTÍFICO ICOMOS BRASIL, 2017, Belo Horizonte. Anais [...]. Belo Horizonte: Instituto Metodista Izabela Hendrix, 2018.

PERETTO, F. T.; SANTORO, P. F.; OKSMAN, S.; MENDONÇA, P. Quando a Transferência de Potencial Construtivo virou mercado: o caso de São Paulo. In: XV SEMINÁRIO DE HISTÓRIA DA CIDADE E DO URBANISMO, 2018, Rio de Janeiro. Anais [...]. Rio de Janeiro: UFRJ, 2018.

REZENDE, V. F. et al. A Outorga Onerosa do Direito de Construir e o Solo Criado. Uma necessária avaliação das matrizes conceituais. Revista brasileira de estudos urbanos e regionais, São Paulo, v. 11, n. 2, p. 51-71, 2009.

ROLNIK, R. (org.). Estatuto da Cidade: guia para implementação pelos municípios e cidadãos. Brasília: Câmara dos Deputados, Coordenação de Publicações, 2002.

SÃO PAULO (Município). Relatórios de Declaração de Potencial Construtivo Passível de Transferência e Certidão de Potencial Construtivo. São Paulo: PMSP, 2020. Disponível em: https://www.prefeitura.sp.gov.br/cidade/secretarias/urbanismo/legislacao/zoneamento/index.php?p=238151. Acesso em: 10 ago. 2020.

. Decreto Municipal n ${ }^{\circ} 58.289$ de 26 de junho de 2018. Regulamenta a TDC com Doação de Imóvel, nos termos dos artigos 123, 126, 127, 128, 130 e 131 da Lei no ${ }^{\circ} 16.050$, de 31 de julho de 2014 - Plano Diretor Estratégico - PDE. Diário Oficial da Cidade: São Paulo: 2018. Disponível em: http://www.docidadesp.imprensaoficial.com.br/NavegaEdicao.aspx?ClipID=97e68a632eb6aofa932c2oc8d2d559d8\&PalavraChave $=58.289$. Acesso em: 10 ago. 2020. 
SÃO PAULO (Município). Lei Municipal n ${ }^{\circ} 16.402$ de 22 de março de 2016. Disciplina o parcelamento, o uso e a ocupação do solo no Município de São Paulo, de acordo com a Lei $\mathrm{n}^{0} 16.050$, de 31 de julho de 2014 - Plano Diretor Estratégico (PDE). Diário Oficial da Cidade: São Paulo, 2016. Disponível em: http://www.docidadesp.imprensaoficial. com.br/NavegaEdicao.aspx?ClipID=2QUAFFO 7 S38BLeER7VNEFPVLQBE\&PalavraChave=16.402. Acesso em: 10 ago. 2020.

Lei Municipal $\mathrm{n}^{\circ} 16.050$ de 31 de julho de 2014. Aprova a política de desenvolvimento urbano e o Plano Diretor Estratégico do Município de São Paulo e revoga a Lei no 13.430/2002. Diário Oficial da Cidade: São Paulo, 2014. Disponível em: http://www. docidadesp.imprensaoficial.com.br/NavegaEdicao.aspx?ClipID=B9N8D6TN3UGAMeE65RHOJ8E9OF7\&PalavraChave=16.050. Acesso em: 10 ago. 2020.

. Portal GeoSampa. Disponível em: http://geosampa.prefeitura.sp.gov.br. Acesso em: 10 ago. 2020.

VILLAÇA, F. São Paulo: segregação urbana e desigualdade. Estudos Avançados, v. 25, n. 71, pp. 37-58, 2011. 


\section{Amanda Paulista de Souza}

Graduada pela Faculdade de Direito da Universidade de São Paulo e mestra em Planejamento Urbano e Regional pela Faculdade de Arquitetura e Urbanismo da mesma instituição. Atualmente é mestranda no Programa de Cidades Inteligentes e Sustentáveis da Universidade Nove de Julho.

Email: apaulista.souza@gmail.com

ORCID: 0000-0002-9368-4581

Contribuição de autoria: conceituação, investigação/pesquisa, metodologia, administração do projeto, supervisão/orientação, validação, visualização, escrita primeira redação.

\section{Flávia Taliberti Peretto}

Graduada em Arquitetura e Urbanismo pela Universidade de São Paulo e mestra em Planejamento Urbano e Regional pela Faculdade de Arquitetura e Urbanismo da mesma instituição.

Email: flaviapereto@gmail.com

ORCID: 0000-0001-9631-006X

Contribuição de autoria: conceituação, curadoria de dados, análise formal, investigação/pesquisa, metodologia, recursos, supervisão/orientação, validação, escrita - primeira redação, escrita - revisão e edição. 


\section{He Nem Kim Seo}

Graduada em Direito pela Universidade Presbiteriana Mackenzie e em Arquitetura e Urbanismo pela Universidade de São Paulo. Mestre em Planejamento Urbano e Regional pela Faculdade de Arquitetura e Urbanismo desta última instituição. Atualmente, é mestranda no programa de Urban Administration and Planning na International School of Urban Science da University of Seoul, Coreia do Sul.

Email: henem.kim@gmail.com

ORCID: 0000-0001-9218-9047

Contribuição de autoria: conceituação, curadoria de dados, análise formal, metodologia, validação, visualização, escrita - revisão e edição.

Submissão: 29 de agosto de 2020.

Aprovação: 30 de novembro de 2020.

Como citar: SOUZA, A. P.; PeReTtO, F. T.; SEO, H. N. K. O Parque Augusta e a multiplicação do potencial construtivo: a TDC para implantação de Parques Municipais no PDE-SP de 2014. Revista brasileira de estudos urbanos e regionais. v. 23, E202102, 2021. DOI 10.22296/2317-1529.rbeur.202102

Artigo licenciado sob Licença Creative Commons CC BY 4.0.

https://creativecommons.org/licenses/by/4.o/deed.pt_BR 